\title{
MI VICO HERMENÉUTICO
}

\section{Leonardo Amoroso (Universidad de Pisa)}

Resumen: Mi lectura de Vico se mueve, en general, en los campos de la Hermenéutica, de la filosofía del lenguaje y de la estética. Un problema específico que me interesa es el del papel de los hebreos en la Ciencia nueva. Palabras Clave: Vico, $350^{\circ}$ Aniversario, hermenéutica, lenguaje, estética, hebraísmo, L. Amoroso.

\section{MY HERMENEUTICAL VICO}

ABSTRACT: My reading of Vico belongs, in general, to the fields of hermeneutics, philosophy of language and aesthetics. A specific problem that interests me is the role of the Hebrews in Scienza nuova.

KEYWORDS: Vico, 350 ${ }^{\text {th }}$ Anniversary, hermeneutics, language, aesthetics, Hebraism, L. Amoroso.

\section{IL MIO VICO ERMENÉUTICO}

RiASSUNTO: La mia lettura di Vico si muove, in generale, nei campi dell'ermeneutica, della filosofia del linguaggio e dell'estetica. Un problema specifico che m'interessa è quello del ruolo degli ebrei nella Scienza nuova. Parole ChiAVE: Vico, $350^{\circ}$ Anniversario, ermenéutica, linguaggio, estetica, ebraismo, L. Amoroso.

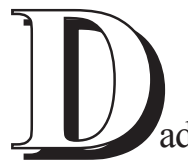

ado el estilo de las contribuciones requeridas para este volumen, no es quizás posible evitar el moi haïssable. Por otro lado, esconderlo, como hace Vico en su autobiografía, detrás de una falsa tercera persona sería un hábito anticuado y un poco ridículo. Usaré, pues, la primera persona. Y ni siquiera evitaré citar algunas de mis publicaciones viquianas, cuando me parezca necesario hacerlo.

En los años en los que me formé, esto es, en los años Setenta del siglo pasado, se estaba en pleno "giro lingüístico». Personalmente lo acogí sobre todo en lo que se refiere a la hermenéutica de inspiración heideggeriana y, subsidiariamente,

Este artículo responde a una invitación expresa por parte de la Dirección de la Revista para este volumen especial por el $350^{\circ}$ Aniversario del nacimiento de G. Vico, habiendo superado los criterios de valoración y del proceso de aceptación. 
en lo referente a la semiología de inspiración saussureana. Es a la luz de estas dos corrientes, y sobre todo de la primera, como he interpretado después a Vico.

Mi asiduo trato con este autor comenzó a finales de los años Ochenta y ha coincidido con años en los que he tenido la fortuna de poder tener una estrecha relación con un gran estudioso de Vico: Ernesto Grassi, al que deseo recordar aquí también por sus extraordinarias dotes humanas. Desde un punto de vista científico, dada mi procedencia desde estudios heideggerianos, un aspecto que me interesaba y me atraía particularmente de Grassi era el hecho de que él proponía una audaz conexión entre Vico y, justamente, Heidegger. Este último había sido uno de los maestros de Grassi. Y posteriormente, inmediatamente después de la segunda guerra mundial, él había entregado precisamente a su ex-discípulo, defensor del humanismo, su Brief über den Humanismus para que lo publicase. Pero la crítica de Heidegger al humanismo como inicio de la «metafísica del sujeto» según Grassi no captaba en absoluto el sentido. El humanismo había sido todo lo contrario y, más bien, ya había hecho afirmaciones que después serían del propio Heidegger, como la crítica a la metafísica tradicional, la centralidad del lenguaje y la importancia de la poesía como fundadora de historia. Dado entonces que Grassi veía en Vico la culminación del humanismo, él podía sostener, por un lado, que Vico era un heideggeriano ante litteram $\mathrm{y}$, por otro, que Heidegger, si lo hubiese conocido, habría encontrado en él un valioso interlocutor. ${ }^{1}$

En otros aspectos, mi «descubrimiento» de Vico en aquellos años se enmarca en los estudios que estaba desarrollando sobre el nacimiento dieciochesco de la estética, en particular con Baumgarten y con Kant. También en estos estudios, por otra parte, jugaba un papel importante mi adhesión a la filosofía hermenéutica. De hecho, mi interés no era solo historiográfico, sino también teorético: me preocupaba mostrar cómo en aquel nacimiento dieciochesco la estética no era en absoluto solo «filosofía del arte bella» (como habría sido la mayoría de las veces en el siglo XIX), sino que tuviese una importancia filosófica mucho más general y justamente con relación a temas que después habrían motivado la unión de estética y hermenéutica en el siglo XX, por ejemplo con Gadamer. Trataba de argumentarlo, entre otras cosas, implicando también a la retórica: si Croce, para mostrar que Vico era el «padre» de la estética, mientras que Baumgarten, en cambio, habría sido solo el «padrino», había olfateado en este último el «moho» de la retórica, de la cual, en cambio, Vico, se habría liberado, ${ }^{2}$ a mí me parecía, también aquí en consonancia

1. Cfr. por ejemplo: ERnesto Grassi, Heidegger e il problema dell'umanesimo, Guida Editori, Nápoles, 1985 e ID., Vico e l'umanesimo, Guerini e Associati, Milán, 1990 [Trad. esp. Heidegger y el problema del humanismo, Anthropos, Barcelona, 2006 y Vico y el humanismo. Ensayos sobre Vico, Heidegger y la retórica, Anthropos, Barcelona, 1999]. Sobre estos temas he discutido también recientemente en mi ensayo «De Heidegger a Vico con Grassi y Gadamer», Cuadernos sobre Vico, n. 30-31, 2016-2017 (XXV Aniversario), pp. 19-30.

2. Cfr. Benedetto Croce, Estetica come scienza dell'espressione e linguistica generale (19417; $1^{\text {a }}$ ed. en 1902), a cargo de G. Galasso, Adelphi, Milán, 1990, p. 275 y pp. 289-295. 
con Grassi (y con otros estudiosos), ${ }^{3}$ que era imposible subestimar la importancia de la retórica en el pensamiento de Vico y acercaba a Baumgarten y Vico precisamente sobre este punto ${ }^{4}$ decisivo para una estética entendida no solo como «filosofía del arte bella».

Por lo demás, el hecho de que la estética de Vico sea además y sobre todo una hermenéutica se puede ver por el significado que el tema de la poesía tiene en la Scienza nuova. No se trata, ante todo, de la poesía de las épocas civilizadas, sino de la poesía de los tiempos primitivos, sustancialmente idéntica, por lo tanto, con el mito. Y esta poesía, o sea, mitología es discutida por Vico leyéndola -de un modo muy original- como expresión de fases arcaicas de la civilización, o mejor dicho como fundadoras de la civilización. Entre los textos poéticos de este tipo siempre han tenido un lugar privilegiado, como objeto de consideración hermenéutica, los poemas homéricos. También Vico los trata en el tercer libro de la Scienza nuova, retomando la vexata quaestio homérica y desarrollándola de un modo que anticipa, al menos en parte, sus desarrollos posteriores. Finalmente, con un paso que de alguna manera puede hacer pensar incluso en la antropología estructural, Vico no solo trata de comparar la mitología griega (de la que los poemas homéricos son testimonio) con las mitologías de otros pueblos, sino también de estudiar la una y las otras como sistemas de signos.

No solo los textos poético-mitológicos, sino, en general, todos los textos en los cuales una comunidad humana se reconoce a sí misma son aquellos a los que la hermenéutica siempre ha dedicado un interés particular. Un segundo grupo de estos textos lo constituyen los jurídicos. También en este caso encontramos una perfecta consonancia en Vico, que también basa la reconstrucción del mundo arcaico sobre la historia del derecho romano, a partir de las XII Tablas. Es más, es precisamente desde el punto de vista de su extraordinario interés hermenéutico como puede ser entendida la singular equivalencia que Vico propone entre aquellas leyes y los poemas homéricos.

Tradicionalmente, un tercer ámbito privilegiado de la hermenéutica, además de aquel relativo a los textos literarios y a los jurídicos, es el que concierne a los textos religiosos. En este sentido, Vico tiene una posición diferenciada. Él sin duda lleva a cabo una hermenéutica de las religiones no bíblicas: esta coincide con la ya nombrada hermenéutica de la mitología (o sea, de la poesía de los «poetas teólo-

3. Pienso, por ejemplo, en Andrea Battistini. Aprovecho la ocasión para decir que fue para mí una feliz coincidencia que justamente en la época en la que afrontaba el estudio sistemático de la Scienza nuova se publicase la edición cuidada precisamente por Battistini de las Opere (Mondadori, Milán 1990). Sin aquellas utilísimas notas, no sé si habría sido capaz de penetrar en la selva de la obra maestra viquiana.

4. Cfr., i.e., mi ensayo Vico, Baumgarten e l'estetica en Nastri vichiani, Edizioni ETS, Pisa, 1997, $2^{\mathrm{a}}$ ed. en 2018 (que contiene además ensayos significativos para mi lectura hermenéutica de Vico, en particular Vico, Spinoza e l'ermeneutica e Vico, Heidegger e la metafisica). De Vico y de los otros «padres» de la estética he discutido también en Ratio \& aesthetica. La nascita dell'estetica e la filosofia moderna, Edizioni ETS, Pisa, 2000, 2ª ed. en 2004. 
gos»). En cambio, no desarrolla una hermenéutica del Nuevo Testamento, lo cual es comprensible porque el período histórico que él considera en la Scienza nuova termina con la segunda guerra púnica y, por lo tanto, precede a la época cristiana. La cuestión del judaísmo es mucho más problemática, una parte de cuya historia se inscribe en el período considerado por Vico. También por esta razón la relación de Vico con el judaísmo me pareció digna de ser investigada más de lo que generalmente se hace. ${ }^{5}$

Ante todo, en relación con el tema aquí mencionado desde el principio, el del lenguaje, se pueden señalar semejanzas entre Vico y la tradición hebrea, en la cual aquel tema es absolutamente central ya en la Biblia (y después, por ejemplo, en la hermenéutica del midrash y en la mística de la qabbalà). Vico es consciente de estas semejanzas al menos parcialmente, por ej. cuando se refiere al hecho de que, como dice el comienzo de la Biblia, es con la palabra como Dios crea. No es casualidad que, como recuerda Vico, davar signifique, en hebreo bíblico, tanto «hecho» como «cosa». Pero, con todas las diferencias de azar, también los hombres «crean»su mundo gracias al lenguaje.

Esta última afirmación, sin embargo, se aplica al lenguaje poético de los gentiles. ¿Y los hebreos? ¿Qué lenguaje y qué sabiduría se les puede atribuir? ¿Una sabiduría poética? ¿Una sabiduría filosófica? ¿Una sabiduría que es a la vez la una y la otra? ¿Una sabiduría que no es ni la una ni la otra? Esta serie de interrogantes está motivada no solo por el hecho de que la posición de Vico, o más bien los propios términos de la cuestión, cambian a lo largo del recorrido que va desde el De antiquissima al Diritto Universale a la Scienza nuova prima hasta la Scienza nuova definitiva, sino también por el hecho de que ni siquiera en esta última parece posible encontrar una respuesta unívoca. Por otro lado, no se puede sostener en absoluto, en mi opinión, que la presencia de los hebreos sea un mero contratiempo en la Scienza nuova, o más bien que sea solo por un escrúpulo religioso que la perspectiva hermenéutico-antropológica de esta obra no se aplique a este pueblo. En cambio, el objetivo de Vico es precisamente reconstruir los orígenes de las naciones gentiles a la luz de la religión que para él es la verdadera, esto es, la bíblica. Pero como el período que consideraba era anterior al advenimiento del cristianismo, la referencia al judaísmo como contexto de referencia es imprescindible, aunque al mismo tiempo muy problemático, hasta el punto de que a Vico le resulta muy difícil gestionarlo.

Concluyendo esta contribución, espero que las pocas páginas que he escrito sean sin embargo suficientes para aclarar el título que he elegido para este número

5. Lo he discutido en varios de mis ensayos, por ejemplo en «Vico e gli ebrei» en mi Scintille ebraiche. Spinoza, Vico e Benamozegh, Edizioni ETS, Pisa, 2004 (donde son además citados los pocos autores que han estudiado este tema, v.g. Donatella Di Cesare). 
de Cuadernos sobre Vico y, al mismo tiempo, los motivos por los que creo que nuestro autor merece, frente a lo que normalmente se entiende, un lugar destacado en la historia de la hermenéutica. ${ }^{6}$

[Traducción del italiano por Jéssica Sánchez Espillaque]

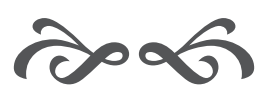

6. Sin embargo hay excepciones: cfr. por ejemplo Stefanie Woidich, Vico und die Hermeneutik, Königshausen \& Neumann, Wurzburgo, 2007. 


$$
350
$$

